\title{
Compreensões da Área de Ciências da Natureza e suas Tecnologias no Referencial Curricular Gaúcho
}

\section{Understanding of the Area of Natural Sciences and its Technologies in the Gaucho Curriculum Reference}

\section{Comprensión del Área de Ciencias Naturales y sus Tecnologías en la Referencia Curricular Gaucha}

Fabiane Habowski (fabihabowski@ gmail.com)

(Programa de Pós-Graduação em Ensino de Ciências - PPGEC - Universidade Federal da Fronteira Sul)

Fabiane de Andrade Leite (fabianeandradeleite@gmail.com)

(Programa de Pós-Graduação em Ensino de Ciências - PPGEC - Universidade Federal da Fronteira Sul)

Resumo: A presente pesquisa objetiva discutir compreensões acerca da área de Ciências da Natureza e suas Tecnologias (CNT) no documento do Referencial Curricular Gaúcho (RCG), com foco na proposta dos itinerários formativos para o Novo Ensino Médio. O estudo é parte de um estudo de natureza qualitativa realizada junto ao Programa de Pós-graduação em Ensino de Ciências (PPGEC) da Universidade Federal da Fronteira Sul - Campus Cerro Largo. O objeto de investigação foi o documento do referencial curricular proposto no Rio Grande do Sul, que busca adequar o currículo à Base Nacional Comum Curricular, aprovada em 2018. No documento observou-se a proposta de flexibilização curricular por meio da possiblidade de escolha de um ou mais itinerários a partir da indicação de nove apresentados na área de CNT. O percurso formativo na área indica compreensões de Ciência balizados na concepção de conhecimento como construção humana e, também, por meio do projeto de vida, pode contribuir para o desenvolvimento de autonomia pelos estudantes. Com o estudo, destaca-se a importância em analisar documentos curriculares no Brasil, tendo em vista as alterações propostas nos últimos anos, porém percebe-se que a realidade da escola ainda está muito aquém do ideal apresentado nos documentos.

Palavras-chave: Políticas Curriculares; Itinerários Formativos; Ensino de Ciências.

Abstract: This research aims to discuss understandings about the area of Natural Sciences and its Technologies in the document of the Gaucho Curriculum Reference, focusing on the proposal of training itineraries for the New High School. The study is part of a qualitative study carried out with the Graduate Program in Science Teaching of the Universidade Federal da Fronteira Sul - Campus Cerro Largo. The object of investigation was the document of the curriculum framework proposed in Rio Grande do Sul, which seeks to adapt the curriculum to the Common National Curriculum Base,

Recebido em: 30/05/2021

Aceite em: 13/08/2021 
approved in 2018. In the document, the proposal for curricular flexibility through the possibility of choosing a or more itineraries from the indication of nine presented in the area. The formative path in the area indicates understandings of Science based on the conception of knowledge as a human construction and, also, through the life project, it can contribute to the development of autonomy by students. The study highlights the importance of analyzing curriculum documents in Brazil, in view of the changes proposed in recent years, but it is clear that the reality of the school is still far from the ideal presented in the documents.

Keywords: Curriculum Policies; Formative Itineraries; Science teaching.

Resumen: Esta investigación tiene como objetivo discutir entendimientos sobre el área de las Ciencias Naturales y sus Tecnologías en el documento de Referencia Curricular Gaucha, centrándose en la propuesta de itinerarios formativos para el Nuevo Bachillerato. El estudio es parte de un estudio cualitativo realizado con el Programa de Posgrado en Enseñanza de las Ciencias de la Universidade Federal da Fronteira Sul Campus Cerro Largo. El objeto de investigación fue el documento del marco curricular propuesto en Rio Grande do Sul, que busca adecuar el currículo a la Base Curricular Nacional Común, aprobado en 2018. En el documento, la propuesta de flexibilidad curricular a través de la posibilidad de elegir uno más itinerarios a partir de la indicación de nueve presentados en el área. El camino formativo en el área indica comprensiones de la ciencia basadas en la concepción del conocimiento como construcción humana y, además, a través del proyecto de vida, puede contribuir al desarrollo de la autonomía de los estudiantes. El estudio destaca la importancia de analizar los documentos curriculares en Brasil, en vista de los cambios propuestos en los últimos años, pero es claro que la realidad de la escuela aún está lejos del ideal presentado en los documentos.

Palabras-clave: Políticas curriculares; Itinerarios formativos; Enseñanza de las ciencias.

\section{INTRODUÇÃO}

O currículo da Educação Básica (EB) brasileira tem sido foco de estudos há mais de vinte anos e, na última década esse processo têm se intensificado, tendo em vista o aumento no número de reformas curriculares propostas. Entre as reformas destacamos a do Ensino Médio (EM) que se consolidou no Brasil a partir da Lei 13.415/2017 e, com isso, fez surgir o Novo EM.

Sob uma perspectiva histórica da educação brasileira, destacamos que nos últimos 20 anos, tendo como foco o EM, têm-se elementos suficientes que evidenciam a incongruência nas políticas educacionais. Após a promulgação da Lei de Diretrizes e Bases da Educação Nacional (LDB) 9394/1996, tivemos o EM Integrado (decreto

Recebido em: 30/05/2021

Aceite em: 13/08/2021 
5.154/2004), o EM Inovador (ProEMI) 2009 a 2011, o EM Politécnico, este último implementado nas escolas gaúchas no ano de 2012, e teve o seu término em 2014, e atualmente, o Novo EM, Lei 13.415/2017.

Dentre tantas reformas pelas quais esta modalidade de ensino já passou, destacamos a iniciada em 2016, por meio da Medida Provisória no 746 (BRASIL, 2016), que trata da criação do Novo EM e promove alterações nesta modalidade de ensino. Sendo que, em fevereiro de 2017, a Lei $\mathrm{n}^{\circ} 13.415$ foi sancionada tornando a Reforma do EM brasileiro algo concreto. Além das aprendizagens comuns e obrigatórias, definidas pela Base Nacional Comum Curricular para o Ensino Médio (BNCCEM), aos alunos foi possibilitado escolher se aprofundar naquilo que mais se relaciona com os seus interesses e talentos, por meio da realização dos itinerários formativos (BRASIL, 2017).

O histórico das discussões propostas para a implantação de um Novo EM no Brasil não é o foco deste estudo, porém destacamos que a Lei é fruto de um intenso e longo processo de redefinição da identidade dessa etapa de ensino, necessária e urgente, tendo em vista incertezas quanto ao que deve ser ensinado.

A caracterização do ensino médio (EM) brasileiro como a etapa final da educação básica (EB), situada entre o ensino fundamental e a educação superior, tem apontado problemas quanto as compreensões acerca de como trabalhar ou do que deve ser trabalhado. As incompreensões geram a dualidade caracterizada por entendimentos diversos, sendo um direcionado para a formação integral do cidadão para o mercado de trabalho, e, outro relacionado a preparação para a etapa posterior, o ingresso no ensino superior. Nessa direção, concordamos com Kuenzer (2009) ao destacar a importância da educação escolar vincular-se ao mundo do trabalho e às práticas sociais, já que a Lei de Diretrizes e Bases da Educação (LDB-9394/1996), em seu primeiro capítulo, defende a educação como totalidade, superando os limites da escola, tendo em vista envolver relações sociais e produtivas.

Se por muitos anos no Brasil finalizar a última etapa da EB era uma perspectiva restrita às camadas privilegiadas da população, nos últimos anos essa realidade se transformou, produzindo grandes desafios. Salientamos, de acordo com Krawczyk (2011, p.757), que "quando os adolescentes realmente aprenderem em sintonia com o 
mundo em que vivem, estaremos diante de um processo real de democratização do ensino e não simplesmente de progressiva massificação".

Quando se trata de refletir sobre o sistema educacional brasileiro, é consensual a percepção de que o Ensino Médio é o nível de ensino que provoca os debates mais controversos, seja pelos persistentes problemas do acesso e da permanência, seja pela qualidade da educação oferecida, ou, ainda, pela discussão sobre a sua identidade (KRAWCZYK, 2011).

O Novo EM tem, entre seus objetivos, o de promover o protagonismo do aluno, a valorização da capacidade criativa dos professores e a permanência escolar por meio de aprendizagem com qualidade (BRASIL, 2017). Após período de observação e ajustes, no ano de 2022, todas as escolas de EM brasileiras já deverão estar com esta nova política educacional implementada.

No que se refere aos Itinerários Formativos observamos que tratam de:

Cada conjunto de unidades curriculares ofertadas pelas instituições e redes de ensino que possibilitam ao estudante aprofundar seus conhecimentos e se preparar para o prosseguimento de estudos ou para o mundo do trabalho de forma a contribuir para a construção de soluções de problemas específicos da sociedade (BRASIL, 2018a, p. 2).

Ainda, os Itinerários previstos no art.36 da LDB, na redação dada pela Lei $n^{\circ}$ 13.415/2017, são "organizados por meio da oferta de diferentes arranjos curriculares, conforme a relevância para o contexto local e a possibilidade dos Sistemas de Ensino" (BRASIL, 2018b, p.14). Para os relatores da proposta, os Itinerários podem se tornar algo bastante inovador, conforme apresentado no parecer $\mathrm{n}^{\circ} 3$ da resolução, ao afirmar que "é uma importante inovação em termos sociais e educacionais" (BRASIL, 2018b, p. 14).

Com isso, destacamos que a proposição de um novo currículo para o EM fez com que os sistemas de ensino estaduais buscassem elaborar referenciais curriculares regionalizados. No estado do Rio Grande do Sul (RS) o processo de implantação do Novo EM vem sendo construído a partir de um documento norteador o Referencial Curricular Gaúcho (RCG), apresentado à comunidade escolar no ano de 2020. O documento, elaborado em regime de colaboração entre a Secretaria Estadual da Educação (SEDUC), a União Nacional dos Dirigentes Municipais da Educação 
(UNDIME) e o Sindicato do Ensino Privado no Rio Grande do Sul (SINEPE/RS), e colaboração dos professores das escolas estaduais, que puderam sugerir habilidades e objetos do conhecimento para as três séries do EM, será o norteador dos currículos de todas as escolas gaúchas de EM a partir de 2022.

A nova matriz curricular do EM gaúcho é formada por uma carga horária de 3.000 horas distribuídas ao longo das três séries e é composta por atividades de Formação Geral Básica (1.800 horas) e pelos Itinerários Formativos (1.200 horas) que fazem parte da flexibilização curricular. O processo de implantação do Novo EM no RS iniciou no ano de 2020 com a realização da escolha de itinerários formativos em 300 escolas piloto.

Nesse sentido, empreendemos o presente estudo, realizado no âmbito do Programa de Pós-graduação em Ensino de Ciências (PPGEC) da Universidade Federal da Fronteira Sul - Campus Cerro Largo. A pesquisa decorre do interesse em discutir as reformas educacionais no Brasil com foco em novas proposições curriculares. Nesse novo contexto de discussão surgem diversos questionamentos, entre as quais destacamos: Quais as compreensões da área de CNT estão apresentadas no documento do RCG com foco nos itinerários formativos propostos?

Destacamos a relevância da investigação por se tratar de uma temática atual, que propõe alteração no currículo da EB brasileira. Nesse sentido, indicamos a necessidade de nos mantermos vigilantes ao processo e, com isso, contribuir para uma melhor compreensão da proposta do Novo EM, tendo em vista que a modalidade é recente e, por isso, a produção científica sobre a temática ainda é incipiente.

\section{A ÁREA DE CIÊNCIAS DA NATUREZA E SUAS TECNOLOGIAS NO BRASIL: ASPECTOS DOCUMENTAIS}

A formação da área de CNT no Brasil é recente, a denominação, abrangendo as disciplinas de Química, Física, Biologia e Matemática, passou a ser usada em 1998, por meio da promulgação das Diretrizes Curriculares Nacionais do Ensino Médio (DCNEM), seguidas dos Parâmetros Curriculares Nacionais para o Ensino Médio (PCN-EM) (1999) e das Orientações Curriculares Nacionais do Ensino Médio (OCN-EM) (2006).

Recebido em: 30/05/2021

Aceite em: 13/08/2021 
Em 2009 tivemos uma alteração significativa na constituição da área apresentada na

Matriz de Referência do Exame Nacional do Ensino Médio (ENEM). No documento a Matemática passou a fazer parte de uma nova área de conhecimento, permanecendo a CNT constituída pelas disciplinas de Química, Física e Biologia (RIO GRANDE DO SUL, 2020).

No que se refere ao que está proposto para a área de CNT no documento da BNCC, destacamos o que apresentam Reis et al. (2021). Para os autores, a área de CNT no documento tem como foco o letramento científico destacando a importância das ações investigativas, sendo que "podem-se entender essas ações investigativas como a promoção da abordagem do ensino por investigação, sendo ele defendido como uma abordagem didática apropriada para o desenvolvimento da alfabetização científica em aulas de Ciências” (REIS et al, 2021, p. 490).

Ainda, cabe destacar, de acordo com Reis et al. (2021, p. 501) que "o documento da BNCC não avança efetivamente em propostas inovadoras para o ensino de Ciências". Nessa mesma linha, Branco e Zanatta, (2021) afirmam que a indicação do ensino de Português e Matemática como únicos obrigatórios no EM no documento da BNCC, "demonstra claramente a possibilidade de redução da carga horária de Ciências nesta etapa da Educação Básica” (BRANCO; ZANATTA, 2021, p. 72).

Quanto ao documento do RCG destacamos que:

\begin{abstract}
A caracterização da área das Ciência da Natureza e suas Tecnologias no Ensino Médio, a partir da BNCC, ocorre pela presença das temáticas Matéria e Energia e Vida, Terra e Cosmos, a partir das quais, junto com as dez competências gerais, e com o aprofundamento e reflexão a respeito das tecnologias e suas perspectivas futuras desdobram-se em três competências específicas (RIO GRANDE DO SUL, 2020, p.13)
\end{abstract}

Desde a proposição da BNCC em 2018, e, com a necessidade de rever seus referenciais curriculares, os estados brasileiros têm buscado construir documentos que contribuem para nortear o processo de implantação nas escolas. Nesse sentido, destacamos o referencial proposto pelo sistema de ensino do Rio Grande do Sul por estarmos diretamente envolvidos com esse contexto.

O RCG propõe nove itinerários formativos em que a área focal é a CNT, sendo eles: Profissões I (Caminhos Rurais), II (Caminhos no Contexto Organizacional Diversidades na Gestão e Negócios) e III (Caminhos na Diversidade da Comunicação e 
Mídias Digitais); Saúde I, II e III e Sustentabilidade I, II e III, apresentados no Quadro

1. Destacamos, ainda, que em cada itinerário há uma área focal e uma área complementar, a área de CNT está como complementar em outros sete itinerários.

Quadro 1- Itinerários formativos, área focal e área complementar

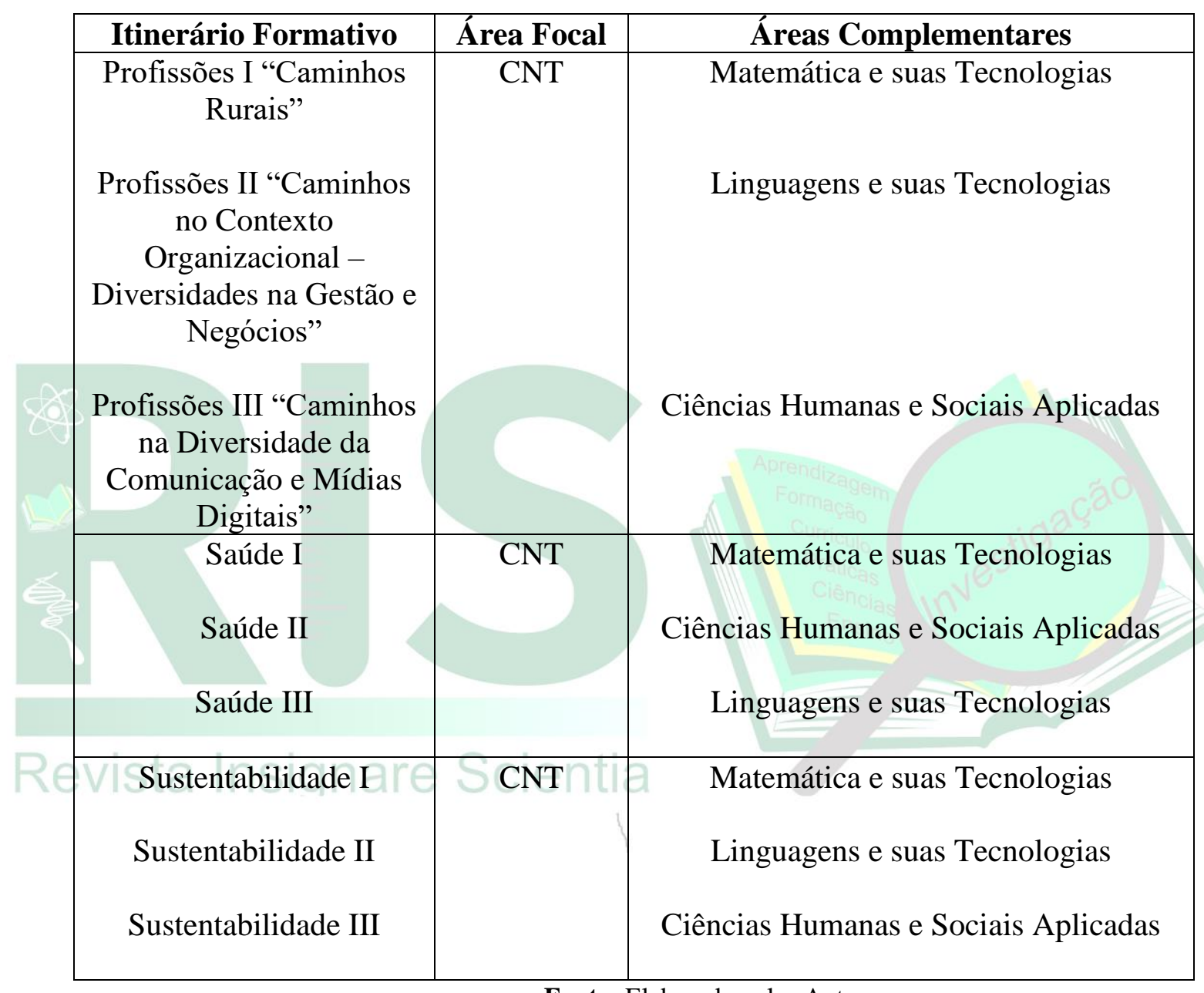

Fonte: Elaborado pelas Autoras.

Salientamos, de acordo com o que está proposto no documento que a carga horária dos itinerários deve corresponder a parte diversificada do que é ofertado no currículo do EM. Sendo que no $1^{\circ}$ ano deve contemplar 200 horas da carga horária anual, no $2^{\circ}$ ano 400 horas e no $3^{\circ}$ ano 600 horas. Assim, na parte comum, ainda, poderá conter aulas de Biologia, Física e Química, como tradicionalmente já são realizadas nas escolas de EB. 
Considerando o foco do presente estudo analisar o que está proposto para a área de CNT por meio dos itinerários formativos, destacamos que o documento do RCG apresenta componentes curriculares específicos a serem realizados, conforme apresentado no Quadro 2.

Quadro 2 - Itinerários formativos da área de CNT e seus respectivos componentes curriculares em cada ano do EM.

\begin{tabular}{|c|c|c|}
\hline Itinerário Formativo & Ano & Componente(s) Curricular(es) \\
\hline $\begin{array}{l}\text { Profissões I "Caminhos } \\
\text { Rurais - Diversidades } \\
\text { do campo" }\end{array}$ & $2^{\circ}$ & $\begin{array}{l}\text {-Gestão da cidadania e do empreendedorismo } \\
\text { sustentável; } \\
\text {-Produção, sistema, manipulação e análise } \\
\text { ambiental na vida do campo; }\end{array}$ \\
\hline & $3^{\circ}$ & - Noções de climatologia básica \\
\hline 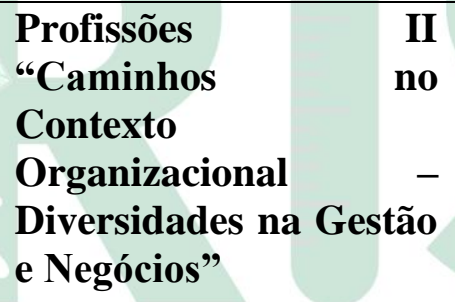 & $1^{\circ}$ & $\begin{array}{l}\text {-Gestão da cidadania e do empreendedorismo } \\
\text { sustentável; } \\
\text {-Gestão ambiental, responsabilidade social e } \\
\text { avaliação de impactos }\end{array}$ \\
\hline vista Insianá & $\begin{array}{l}1^{\circ} \mathrm{C} \\
2^{\circ} \\
3^{\circ}\end{array}$ & $\begin{array}{c}\text { Pn -Estrutura e Funcionamento da Máquina } \\
\text { Humana } \\
\text { - Saúde e Práticas Preventivas } \\
\text { - Nutrição e Prevenção de Doenças; } \\
\text { - Biotecnologias; } \\
\text { - Projeto Investigativo; } \\
\text {-Noções de Farmacologia }\end{array}$ \\
\hline $\begin{array}{l}\text { Sustentabilidade I, II, e } \\
\text { II }\end{array}$ & $1^{\circ}$ & $\begin{array}{c}\text {-Biodiversidade; } \\
\text {-Noções de legislação Ambiental; } \\
\text {-Uso consciente das energias; } \\
\text {-Gestão Ambiental; } \\
\text { - Ciclo de vida dos materiais; } \\
\text { - Inovação Tecnológica; } \\
\text { - Projetos Sustentáveis }\end{array}$ \\
\hline
\end{tabular}

Fonte: Elaborado pela Autoras. 
Tendo como base os objetivos elencados em cada itinerário, os componentes curriculares e os objetos do conhecimento indicados no documento do RCG para a área de CNT, realizamos o presente estudo, caracterizado como de natureza qualitativa, conforme proposto por Lüdke e André (2001). Para o estudo, analisamos o texto apresentado no RCG por meio de sucessivas leituras empreendidas na íntegra de toda a parte correspondentes a área de CNT. Na sequência apresentamos a discussão das compreensões levantadas por meio do processo de análise.

\section{COMPREENSÕES ACERCA DA ÁREA DE CNT NO REFERENCIAL CURRICULAR GAÚCHO}

O processo de materialização da reforma do EM no Brasil, discutido de forma mais intensa na última década, se consolidou por meio da Lei Federal 13.415/2017. Porém, conforme Gonçalves (2017, p. 134), a reforma surpreendeu a todos, pois "foi por meio da Medida Provisória 746, publicada em 22 de setembro de 2016, que a sociedade brasileira tomou conhecimento das mudanças que estavam sendo pensadas para essa etapa da EB". Com isso, entendemos que, mesmo diante de um processo de reformulação do EM brasileiro extremamente necessário, o caminho traçado para a construção nas escolas teve um início conturbado, pois não reconhecemos as medidas provisórias como sustentação para mudanças educacionais tão significativas no Brasil.

Ao mesmo tempo, compreendemos que a sociedade brasileira precisa construir posicionamentos acerca da forma como as decisões têm sido tomadas. Nesse sentido, temos nos preocupado em analisar os discursos escritos e externalizados por todos aqueles que estão diretamente relacionados com as políticas educacionais, em especial com a política de implantação do Novo EM. Assim, buscamos apresentar aqui o que é apresentado no RCG, documento norteador do currículo para o EM no Rio Grande do Sul.

O RCG é um documento que vem para contribuir no processo de construção de novas perspectivas curriculares nos contextos de ensino, as mudanças, o movimento gerado na escola a partir de uma nova proposta, é extremamente significativo. Porém, não podemos ignorar aspectos que marcam os interesses que circundam as propostas e,

Recebido em: 30/05/2021

Aceite em: 13/08/2021 
por isso, buscamos nos manter vigilantes ao processo de construção de novas políticas curriculares.

Tendo como foco a área de CNT destacamos que o documento propõe que "a ciência é uma construção humana, inacabada e em constante modificação, a qual possibilita que o aluno interaja melhor com a sua realidade, compreendendo-a e podendo assim contribuir com as demandas ali presentes" (RIO GRANDE DO SUL, 2020, p. 12). Quanto a essa perspectiva, entendemos que, sim, a Ciência é uma construção humana que vem ocorrendo em diferentes contextos sociais, históricos e culturais. Os estudos da área proporcionam ao aluno essa percepção, ao passo que desenvolvem também a curiosidade, a análise crítica e reflexiva, a argumentação, a ética e a responsabilidade consigo mesmo, com os outros e com a Natureza.

Nesse sentido, considerando que o RCG foi construído a partir do que está proposto na BNCC, concordamos com Sipavicius e Sessa (2019), ao afirmarem que não enfatiza os embates deste processo histórico, e a importância na construção de uma sociedade justa, democrática e inclusiva. Tal característica observada, também no documento curricular gaúcho aponta para um reducionismo na área de CNT, no tocante aos conhecimentos históricos e, também, que relacionam Ciência, Tecnologia e Sociedade.

Ainda, destacamos que, conforme o RCG o aluno poderá apropriar-se - ao longo do Ensino Médio - das linguagens específicas das Ciências, por meio da interlocução destas com a linguagem cotidiana, com os saberes populares, com as demandas de suas comunidades e com os avanços tecnológicos (RIO GRANDE DO SUL, 2020). Porém, concordamos com Lima Júnior (2021, p. 70), que a proposta do Novo EM "apega-se à ideia de competências e habilidades na elaboração do currículo como preparação ao mundo do trabalho".

O documento possui um forte teor mercadológico, seja na proposta dos itinerários formativos para a área de CNT, todos com forte tendência a formação voltado para o mercado de trabalho. Como pode ser observado na proposição dos componentes curriculares, entre os quais destacamos Gestão da cidadania e do empreendedorismo sustentável, como um dos componentes a ser inserido por meio dos itinerários Recebido em: 30/05/2021

Aceite em: 13/08/2021 
Profissões 1, II e III. Os termos Gestão e empreendedorismo indicam a intencionalidade do que está sendo proposto, potencializar uma formação do jovem para o mercado de trabalho.

Não estamos criticando que o jovem brasileiro não deva pensar e realizar as escolhas profissionais desde cedo, ainda, defendemos que o EM deve contribuir para que esse período seja mais profícuo à vida do cidadão. Porém, não compactuamos com propostas carregadas de intencionalidade empresarial, acreditamos que a escolha precisa estar ligada aos interesses dos próprios jovens, e não aos interesses econômicos que regem o sistema brasileiro.

De acordo com Branco e Zanatta (2021, p.71), percebe-se no documento a “organização do ensino voltado para o desenvolvimento de competências e habilidades cria condições para uma "terceirização da educação", sem a devida valorização dos contextos e realidades locais".

Também, observamos nos itinerários Saúde I, II e III a apresentação dos componentes curriculares: Estrutura e Funcionamento da Máquina Humana e Noções de farmacologia, entre outros, que, também, evidenciam o fortalecimento de conhecimentos técnicos ligados à área de CNT. Tais elementos evidenciam o que é destacado por Branco e Zanatta (2021, p. 70), "no tocante ao ensino de Ciências, se configura numa listagem de conteúdos a ser aplicado pelos professores e, além disso, não apresenta propostas pedagógicas que superem as atuais, estabelecidas há vários anos na educação".

Destarte, enfatizamos que o documento do RCG voltado a atender as prerrogativas propostas na BNCC no que se refere ao Novo EM, está pautado em fortalecer uma formação tecnicista, em que priorizam competências e habilidades a serem desenvolvidas no tocante ao ensino de Ciências. Competências direcionadas em atender políticas orçamentárias no Brasil com foco no desenvolvimento de mão de obra.

Ainda, destacamos que o documento apresenta de forma específica os conhecimentos da Biologia que buscam "compreender, o funcionamento dos organismos vivos, a relação desses seres com o meio e seu processo de evolução na Terra" (RIO GRANDE DO SUL, 2020, p. 14). Também, da Química em que "se intenciona que o estudante tenha uma compreensão dos processos químicos em estreita Recebido em: 30/05/2021

Aceite em: 13/08/2021 
relação com suas aplicações tecnológicas, ambientais e sociais, tomando decisões de maneira responsável e crítica, nos níveis individual e coletivo" (RIO GRANDE DO SUL, 2020, p. 19). E é proposto à Física que, “embora a linguagem matemática seja indissociável deste componente curricular, é evidenciada a necessidade de um maior desenvolvimento da ciência investigativa onde a observação, a análise, a coleta de dados e a experimentação, tenham mais relevância frente a simples aplicação de fórmulas" (RIO GRANDE DO SUL, 2020, p.16).

Nos excertos observamos compreensões que repetem aspectos já indicados nos Parâmetros Curriculares Nacionais (PCN) de 1998. Quanto a isso, nos preocupamos com relação aos avanços na área, nos parece que o ensino da de CNT não propõe nada de inovador nos últimos 20 anos, o que não concordamos. Ainda, que para a Química identificamos uma indicação para o desenvolvimento crítico e a tomada de decisões, no tocante aos objetos de conhecimento propostos nos componentes curriculares percebemos limitações, são poucos conceitos específicos que tratam da linguagem química presentes no documento do RCG.

Ainda, acerca dos componentes curriculares dos Itinerários Formativos para a área de CNT percebemos a inserção de novos objetos do conhecimento, aos quais os professores da área também deverão organizar-se em um viés interdisciplinar. Porém, reconhecemos que a formação do professor pode incidir diretamente nas escolhas realizadas, ou seja, o professor formado em Biologia contemplará de forma mais intensa os conceitos deste componente, enquanto o professor de Química ou de Física fará o mesmo para os conceitos específicos de seus componentes curriculares. Aqui resta-nos levantar os questionamentos: a formação inicial que tem sido realizada em cursos de licenciatura específicos da área de CNT dará conta de atender as necessidades desse novo EM? Os conceitos específicos de cada componente, que constitui a área, serão construídos pelo futuro professor de forma geral? Que prejuízos para a formação científica estão por trás dessa proposta?

Diante disso, corroboramos a ideia de Massoni et al, 2021 quando mencionam:

Não restam dúvidas de que é fundamental oferecer oportunidades de vivências interdisciplinares a ocorrer no interior dos nove (9) Itinerários desenhados para a Área de Ciências da Natureza; certamente contribuirão para uma formação cidadã crítica. Contudo, defendemos que uma formação

Recebido em: 30/05/2021

Aceite em: 13/08/2021 
disciplinar é necessária, até mesmo para garantir que os "projetos integradores" previstos nos Itinerários da área possam se desenvolver com o suporte disciplinar sólido e que o estudante adquira profundidade de conhecimentos para se encaminhar com mais segurança para o mercado de trabalho, ou para o Ensino Superior, conforme seu projeto de vida (MASSONI et al, 2021, p.592).

Portanto, reconhecemos o esforço na construção de um documento curricular para o sistema de ensino do RS, entretanto não reconhecemos o que está proposto no texto como uma construção democrática em que participaram os principais envolvidos no processo, professores e alunos. Os interesses que transparecem, por meio dos itinerários formativos elencados e, também, pelos componentes curriculares apresentados, direcionam as intencionalidades do RCG para o desenvolvimento de um jovem formado para o mercado de trabalho condicionado aos interesses estatais que regem as políticas públicas no Brasil.

Dessa forma, somos da prerrogativa de nos mantermos vigilantes e críticos com relação ao que tem sido imposto pelo governo brasileiro na última década. A crítica é necessária para que possamos alertar os contextos em que as políticas curriculares são colocadas em ação e, com isso, nos somar aos tantos professores que se sentem não representados pelo currículo proposto. Nossas intenções se convergem no intuito de contribuir com a discussão acerca do Novo EM no Brasil, e, promovam a construção de discursos que auxiliem no movimento necessário e profícuo de reestruturação do currículo escolar brasileiro.

\section{CONSIDERAÇÕES FINAIS}

No presente estudo buscamos analisar o documento RCG em específico na área de CNT, com enfoque nos Itinerários Formativos, como também nos novos componentes curriculares que surgiram a partir da flexibilização curricular proposta pela política educacional do Novo EM. Compreendemos que a proposição de referenciais curriculares pode contribuir no processo de construção de novas perspectivas curriculares nos contextos de ensino, as mudanças, o movimento gerado na escola a partir de uma nova proposta contribuir com uma reforma legítima para o EM brasileiro.

Ao analisarmos o que está colocado no RCG identificamos divergências nas compreensões direcionados ao trabalho na área de CNT. Destacamos que as discussões Recebido em: 30/05/2021

Aceite em: 13/08/2021 
realizadas ao longo dos últimos 20 anos para qualificar os processos de ensino e de aprendizagem em Biologia, Física e Química não foram considerados. Ainda, destacamos um direcionamento extremo dos itinerários formativos e componentes curriculares para uma formação técnica voltada ao mercado de trabalho.

Salientamos que, ainda, as escolas poderão não escolher itinerários em que a área focal seja a CNT, porém entendemos que os itinerários propostos nas demais áreas não devem estar muito longe das intencionalidades indicadas neste estudo. Também, reconhecemos uma perda de espaço no que se refere ao trabalho com os conhecimentos científicos da área no EM caso a escola não escolha um itinerário da área, o que é preocupante.

Portanto, salientamos que a política do Novo EM trouxe grandes desafios abarcando perspectivas de possibilidades que buscam a inovação nos processos de ensino e de aprendizagem nesta etapa de ensino. No entanto, o que observamos no documento do RCG com foco na área de CNT é um total descaso aos anos de estudos realizados pela comunidade científica e, com isso, um afastamento cada vez maior das necessidades formativas para o jovem brasileiro.

\section{REFERÊNCIAS}

BRANCO, E.; ZANATTA, S. BNCC e Reforma do Ensino Médio: implicações no ensino de Ciências e na formação do professor. Revista Insignare Scientia - RIS, v. 4, n. 3, p. 58-77, 3 mar. 2021.

BRASIL, Medida Provisória $\mathbf{n}^{\mathbf{7}} \mathbf{7 4 6 / 2 0 1 6}$. Promove as alterações no Ensino Médio, publicada no Diário Oficial da União, edição extra nº 184. Disponível em: http://portal.mec.gov.br/ultimas-noticias/211-218175739/39621-publicada-a-medidaprovisoria-que-reformula-o-ensino-medio . Acesso em 10 mar. 2021.

BRASIL. - LEI N..$^{\circ}$ 13.415, de 16 de Fevereiro de 2017- Diário Oficial da União Seção 1 - 17/2/2017, Página 1 (Publicação Original)

BRASIL. Base Nacional Comum Curricular: Ensino Médio. Brasília: MEC/Secretaria de Educação Básica, 2018.

BRASIL. Resolução n. ${ }^{\circ}$ 3, de 21 de Novembro de 2018. Atualiza as Diretrizes Curriculares Nacionais para o Ensino Médio.

GONÇALVES, S. da R. V. Interesses mercadológicos e o "novo" ensino médio.

Retratos da Escola, v. 11, n. 20, p. 131-145, 2017.

Recebido em: 30/05/2021

Aceite em: 13/08/2021 
KRAWCZYK, N. Reflexão sobre alguns desafios do Ensino Médio hoje. Cadernos de Pesquisa. Set/Dez, 2011.

KUENZER, A.Z. (Org) Ensino Médio, construindo uma proposta para os que vivem do trabalho. São Paulo: Cortez, 2009.

LIMA JUNIOR, P. Percursos profissionais de cientistas e professores de Ciências.

Revista Educar Mais, v. 5, n. 3, p. 453-460, 2021.

LÜDKE, M; ANDRÉ, M. Pesquisa em educação: abordagens qualitativas. São Paulo: EPU, 2001.

MASSONI, N.T; BRITO, A.A; CUNHA, A.M. Referencial Curricular Gaúcho para o Ensino Médio 2021: contexto de produção, ciências da natureza e questões étnicoraciais. Revista Educar Mais, v. 5, n.3, p. 583-605, 2021.

REIS, A.; APOLINÁRIO DE AZEVEDO, E.; FREGUGLIA, J.; SCARABELLI RIBEIRO, L. BNCC e as práticas epistêmicas e científicas nos anos finais do ensino fundamental. Revista Insignare Scientia - RIS, v. 4, n. 3, p. 487-503, 3 mar. 2021.

RIO GRANDE DO SUL. Secretaria Estadual de Educação - SEDUC-RS. Referencial Curricular Gaúcho. 2020. Disponível em: http://curriculo.educacao.rs.gov.br/. Acesso em: 23 maio. 2021.

SIPAVICIUS, B. K. de A.; SESSA, P. da S. A Base Nacional Comum Curricular e a área de Ciências da Natureza: tecendo relações e críticas. Atas de Ciências da Saúde, São Paulo, v. 7, p. 03-16, jan./dez. 2019.

Recebido em: 30/05/2021

Aceite em: 13/08/2021 